\title{
Hepatitis-associated Antigen and Antibody in Uganda: Correlation of Serological Testing with Histopathology
}

\author{
P. P. ANTHONY, \\ C. L. VOGEL, \\ F. SADIKALI, \\ L. F. BARKER, \\ M. R. PETERSON
}

British Medical fournal, 1972, 1, 403-406

\section{Summary}

Histopathological findings in 91 Ugandan patients with cirrhosis were studied in relation to serological tests for the hepatitis-associated antigen (H.A.A.) and antibody (anti-H.A.A.). H.A.A. was present in $30(32.9 \%)$ of the 91 patients as opposed to $7(3.1 \%)$ out of 224 controls drawn from the same population $(P<0.001)$. Younger subjects and males were more frequently positive. There was no difference in the presence of anti-H.A.A. between patients and controls. Correlation of the results of serological testing with histopathological features showed that macronodular ("posthepatitic," "postnecrotic") types of cirrhosis, which predominate in Uganda, were associated with the presence of H.A.A. but that the much less common micronodular ("nutritional," fatty, portal) type of cirrhosis was not. Evidence was found, on the other hand, for a direct role of alcoholism in the latter. Detailed histological analysis also showed two types of cellular change-liver cell swelling and dysplasia-to be associated with the presence of $H$.A.A. The data suggest an aetiological role for H.A.A. in most cases of cirrhosis in Uganda and these may be identified by histological criteria.

\section{Introduction}

Histopathological studies of the cirrhotic liver in the past twenty years have led to a bewildering variety of classifications ranging from the purely descriptive to the highly speculative (Popper, 1966). The progression of acute viral hepatitis to macronodular (posthepatitic, postnecrotic) types of cirrhosis has been documented occasionally, and the association of micronodular (fatty, portal) cirrhosis with alcoholism is widely accepted (Sherlock, 1968). Transitions, however, from one anatomical type to another do occur and such observations have been held to indicate that all types of cirrhosis are but points along a continuous spectrum (Scheuer, 1968).

Extensive evidence has accumulated in recent years for the association of a blood-borne antigen with acute viral hepatitis (Shulman, 1970). This hepatitis-associated antigen (H.A.A.), also named the Australia antigen and serum-hepatitis antigen, has provided a new approach for the investigation of the aetiology of chronic liver disease. It has been found to be present in a significant proportion of patients with chronic active hepatitis, cirrhosis, and primary hepatocellular carcinoma (Prince, Leblanc, Krohn, Masseyeff, and Alpert, 1970).

Makerere University, Kampala, Uganda

P. P. ANTHONY, M.B., B.S., M.R.C.PATH., Senior Lecturer, Department of Pathology (Present address: Bland-Sutton Institute of Pathology, MiddlePathology (Present address: Bland-Sutton Institute

C. L. VOGEL, M.D., Director, Solid Tumour Centre, Uganda Cancer Institute

F. SADIKALI, M.B., B.S., M.R.C.P., Lecturer, Department of Medicine

Laboratory of Viral Immunology, Division of Biologics Standards, National Institutes of Health, Bethesda, Maryland, U.S.A.

L. F. BARKER, M.D., Senior Investigator

M. R. PETERSON, M.D., Investigator (Present address: Langley Porter Institute, University of California Medical Center, San Francisco, California, U.S.A.)

Little information exists about whether the presence of H.A.A. in cirrhosis has any bearing on histopathological features. In Uganda cirrhosis is a common disease, and in a previous study a significant association was found with H.A.A. (Maynard, Sadikali, Anthony, and Barker, 1970). The purpose of this paper is to report the results of serological testing for H.A.A. and antibody to H.A.A. (anti-H.A.A.) in a larger number of Ugandan cirrhotic patients and to correlate these results with a detailed analysis of histopathological features.

\section{Patients and Methods}

Ninety-one Ugandan Africans with histologically proved cirrhosis were studied. Thirty-two of these also had primary hepatocellular carcinoma. Those with and without tumour were evaluated separately but the results are presented for the series as a whole except where a significant difference has been found. All patients were admitted to Mulago Hospital, Kampala, or the Solid Tumour Centre of the Uganda Cancer Institute. A history consistent with previous hepatitis, blood transfusion, or alcoholism was sought in all of them.

The controls consisted of 224 patients suffering from various diseases with or without liver involvement who had been admitted to the medical wards of Mulago Hospital, Kampala. An attempt was made to match these as far as age, sex, tribe, socioeconomic status, and residence were concerned.

\section{ASSAYS FOR H.A.A. AND ANTI-H.A.A.}

Samples of blood were collected from all patients and the sera were stored at $-20^{\circ} \mathrm{C}$ before transport in dry ice to Bethesda, Maryland, where the assays were done blind. All samples were tested for the presence of H.A.A. and anti-H.A.A. by complement fixation and counter-electrophoresis techniques for H.A.A. and the passive haemagglutination method for anti-H.A.A. (Shulman and Barker, 1969; Gocke and Howe, 1970; Vyas and Shulman, 1970). Testing for H.A.A. and anti-H.A.A. by immunodiffusion was abandoned after our initial studies because of its relative lack of sensitivity.

\section{HISTOPATHOLOGY}

Tissue specimens were obtained initially by percutaneous needle biopsy, which was supplemented by open laparotomy biopsy in 17 patients and by necropsy in 23. After formalin fixation and routine paraffin processing sections were cut at $5 \mu \mathrm{m}$ and stained with haematoxylin and eosin, Gordon and Sweet's method for reticulin, Mallory's trichrome, and Perls's method for free iron as required. The sections were examined without knowledge of the serological results. In case of doubt slides were referred to an independent panel of pathologists and a consensus of opinion was obtained.

Types of cirrhosis were defined by using the criteria of Gall (1960). It must be emphasized that his terms are used in a descriptive sense only, without acceptance of aetiological implications. The main characteristics of his types are given below.

(a) "Nutritional" cirrhosis (synonyms: micronodular, Laennec's, portal, fatty, or alcoholic). The liver is normal in size or is enlarged with evenly sized nodules of lobular or sublobular size and a fine 
meshwork of connective tissue septa. Fatty change is common and Mallory's alcoholic hyaline may be present.

(b) "Posthepatitic" cirrhosis (synonyms: macronodular, incomplete septal or trabecular). The liver is normal or slightly reduced in size, with variably sized nodules often several centimetres across and long, slender connective tissue septa.

(c) "Postnecrotic" cirrhosis (synonyms: macronodular, postcollapse, toxic). The liver is usually reduced in size, with variably sized, often very large nodules and coarse, broad scars.

(d) In a variable proportion of cases mixtures of the above characteristics may be found which then constitute a "mixed" cirrhosis category. In our experience this comprised cases with predominantly posthepatitic features with a mixture of nutritional in a few and postnecrotic in most.

A detailed histological assessment was carried out to include the presence and degree of liver cell swelling, piecemeal necrosis, inflammation, scarring, and bile duct proliferation. The amount of free iron was also recorded. Each of these was given a score of 0 to 3. Material suitable for such detailed analysis was available in only 55 cases. Patchy liver cell swelling in a cirrhotic liver is illustrated in Fig. 1.

The presence of what we have termed "liver cell dysplasia" was also studied. This was defined as the presence of groups or nodules of liver cells showing nuclear and cytoplasmic enlargement, gross nuclear pleomorphism, and double nuclei or occasional mitoses (Fig. 2).

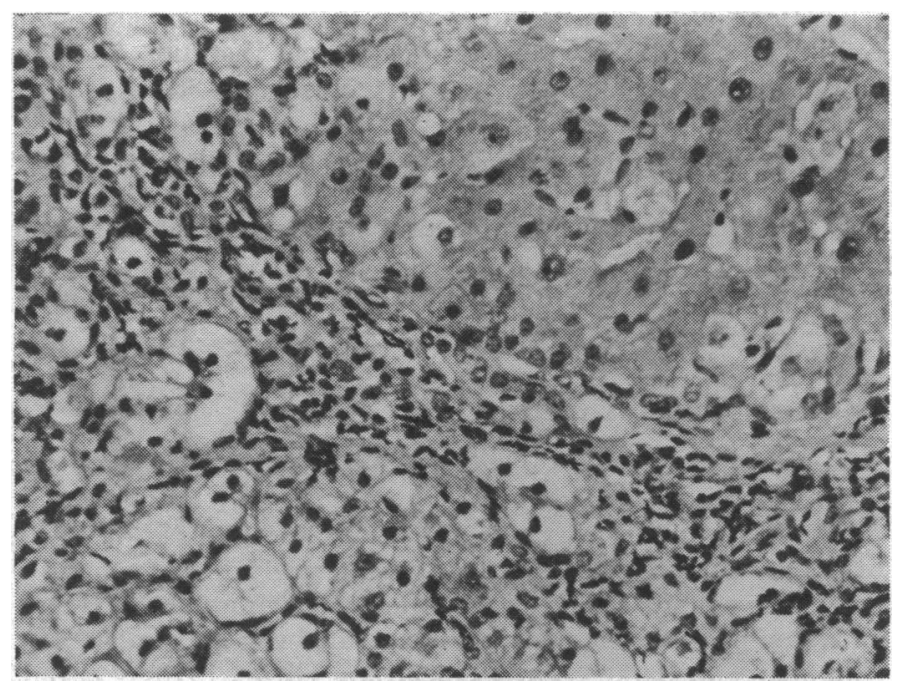

FIG. 1-Patchy liver cell swelling (ballooning) at the edge of and within cirrhotic nodules. (Haematoxylin and eosin. $\times 210$.)

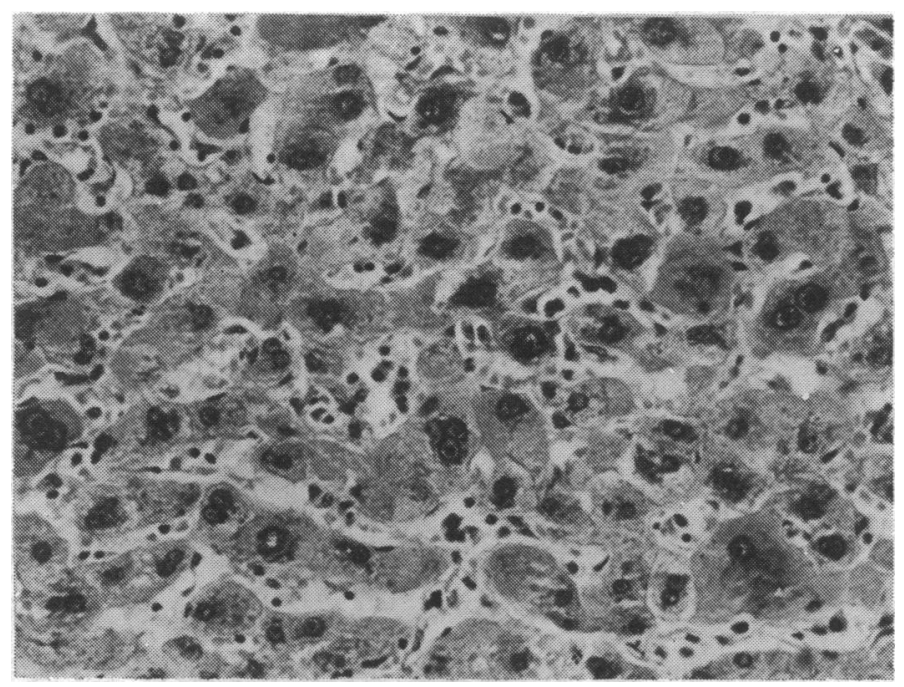

FIG. 2-Gross liver cell dysplasia with nuclear and cytoplasmic enlargement, nuclear pleomorphism, and double nuclei. (Haematoxylin and cosin. $\times 210$.)
Statistical analysis was done by using the $\chi^{2}$ test. Differences were considered significant when $\mathbf{P} \leqslant 0.05$.

\section{Results}

The summary of serological results is shown in Table I. The difference in the presence of H.A.A. between cirrhotic patients $(32.9 \%)$ and controls $(3 \cdot 1 \%)$ is highly significant $(P<0.001)$. Seropositive control cases included two of peptic ulcer and one each of tropical splenomegaly syndrome, chronic myeloid leukaemia, diabetes mellitus, acute pancreatitis, and viral pneumonia. The apparent increase of antigenaemia in patients with cirrhosis and hepatocellular carcinoma (43.7\%) compared with patients with cirrhosis alone $(27 \cdot 1 \%)$ is not statistically significant.

TABLE I-Results of Serological Testing in 91 Cirrhotic Patients with or without Hepatocellular Carcinoma

\begin{tabular}{l|c|c|c}
\hline & Number & H.A.A. Present & Anti-H.A.A. Present \\
\hline $\begin{array}{l}\text { Cirrhosis alone } \\
\begin{array}{l}\text { Cirrhosis with primary } \\
\text { hepatocellular } \\
\text { carcinoma }\end{array}\end{array}$ & 59 & $16(27 \cdot 1 \%)$ & $22(37 \cdot 2 \%)$ \\
\hline $\begin{array}{l}\text { Total } \\
\text { Controls }\end{array}$ & 32 & $14(43.7 \%)$ & $6(18 \cdot 7 \%)$ \\
\hline
\end{tabular}

In contrast to the results of serological tests for H.A.A., no difference was found in the presence of anti-H.A.A. between cirrhotics $(30.7 \%)$ and controls $(30.8 \%)$. More patients with cirrhosis alone were positive $(37.2 \%)$ than patients with cirrhosis and hepatocellular carcinoma (18.7\%) but this difference is not statistically significant.

Persistence of H.A.A. in the presence of antibody was found in 6 out of 91 patients with cirrhosis (all without tumour) in contrast to controls, where antigen and antibody were present together in only 1 out of 224 cases $(P<0.01)$.

Socioeconomic Status, Age, and Sex.-All patients and controls were of low socioeconomic status (classes IV and V of the Registrar General in the United Kingdom). Cirrhosis was distributed in all age groups, with a range of 12 to 65 years and a mean of 38.8 years. This contrasts with experience in Western countries where cirrhosis is predominantly a disease of middle age and beyond. The ratio of males to females for the whole series was $2: 1$. No significant differences were found in age and sex when comparing those with and without tumour. If patients are grouped into those under the age of $\mathbf{4 0}$ and those aged $\mathbf{4 0}$ and over, in the former group $23(45.1 \%)$ out of 51 were H.A.A.positive as compared with only $7(17.9 \%)$ out of 39 in the latter $(P<0.025)$. As regards sex, $25(42 \%)$ out of 59 males were seropositive for H.A.A. as compared with $5(16 \%)$ out of 32 females $(P<0.05)$. The presence of anti-H.A.A., on the other hand, was evenly distributed in all ages and in both sexes.

History of Previous Hepatitis or Transfusion.-Previous hepatitis, as judged by a history of jaundice, could not be correlated with the presence or absence of H.A.A. or anti-H.A.A. either in cirrhotic patients or in controls. Patients who had had blood transfusions were specifically excluded from the group with cirrhosis alone, and in the cirrhosis plus hepatocellular carcinoma group only three patients had been previously transfused. All three were seronegative for both H.A.A. and antiH.A.A.

Types of Cirrhosis, H.A.A., and Anti-H.A.A.-The association of H.A.A. with various types of cirrhosis is presented in Table II. While all 11 patients with H.A.A. were negative, 30 out of 80 patients with other types of cirrhosis were H.A.A.-positive $(P<0.05)$. There were no significant differences in H.A.A. prevalence between posthepatitic, postnecrotic, and mixed types. No significant differences emerged between the type of cirrhosis and anti-H.A.A. 

TABLE II-Morphological Types of Cirrhosis (using Gall's Descriptive Criteria)
in Patients with H.A.A.

\begin{tabular}{|c|c|c|c|c|c|c|c|}
\hline \multicolumn{6}{|c|}{ Type of Cirrhosis } & \multirow{2}{*}{$\begin{array}{c}\text { Number } \\
11 \\
36 \\
7 \\
37\end{array}$} & \multirow{2}{*}{$\begin{array}{c}\text { H.A.A. Present } \\
0 \\
13 \\
4 \\
13\end{array}$} \\
\hline $\begin{array}{l}\text { Nutritional } \\
\text { Posthepatitic } \\
\text { Postnecrotic } \\
\text { Mixed . . }\end{array}$ & $\begin{array}{l}\cdots \\
\cdots \\
\cdots\end{array}$ & $\begin{array}{l}\cdots \\
\cdots \\
\cdots\end{array}$ & $\begin{array}{l}\cdots \\
\cdots \\
\cdots \\
\end{array}$ & $\begin{array}{l}\cdots \\
\cdots \\
\cdots\end{array}$ & $\begin{array}{l}\cdots \\
\cdots \\
\cdots\end{array}$ & & \\
\hline Total & . & $\ldots$ & $\ldots$ & $\ldots$ & . & 91 & 30 \\
\hline
\end{tabular}

Fat, Alcoholic Hyaline, and History of Alcoholism.-Appreciable amounts of fat or alcoholic hyaline were seen only in the 11 cases with nutritional cirrhosis. Six out of eight patients in this group with a history of severe alcoholic abuse showed pronounced fatty change and abundant alcoholic hyaline. In contrast, a history of severe alcoholism was obtained in only 9 out of 80 patients with other types of cirrhosis $(P<0.001)$. Only two of these showed small amounts of fat and none the presence of alcoholic hyaline.

Iron.-Free iron was seen in only two cases of cirrhosis.

Histological Features of Cirrhosis and H.A.A.-Of all the histological features quantitated, only one, liver cell swelling, showed a relation to the presence of H.A.A. When scores of $0-3$ were divided into two groups -1 or less and 2 or more-and correlated with the presence or absence of H.A.A. this relation between liver cell swelling and H.A.A. was found to be statistically significant $(P<0.001)$. Piecemeal necrosis and inflammation were also commoner in seropositive cases but this was not statistically significant. There were no significant correlations between the degree of scarring, bile duct proliferation, and the presence of H.A.A.

Liver Cell Dysplasia.-Liver cell dysplasia was seen in 32 of the whole series of 91 cirrhotic patients with or without hepatocellular carcinoma. H.A.A. was present in $21(66 \%)$ of these 32. In contrast only $10(17 \%)$ out of the 59 patients without dysplasia were seropositive for H.A.A. $(P<0.001)$. Dysplastic changes are less often found in cirrhotic patients without tumour $(13(22 \%)$ out of 59$)$ than in those with tumour $(19(60 \%)$ out of 32). If dysplasia, however, is correlated with antigenaemia separately in the two groups the percentage of H.A.A.-positives is virtually the same: $69^{\circ} \circ$ and $60^{\circ} \%$. Antigenaemia and dysplasia were found in a similar distribution in the posthepatitic, postnecrotic, and mixed types of cirrhosis. Neither antigenaemia nor dysplasia was present, however, in the nutritional group. It is of further interest that dysplasia was present in five of the six patients who had positive tests for both H.A.A. and anti-H.A.A.

\section{Discussion}

Cirrhosis is probably a common disease in Uganda though its exact prevalence is not known and one has to rely on necropsy experience. Shaper (1970) found that in Mulago Hospital cirrhosis was present at necropsy in $9.3 \%$ of males and $3.3 \%$ of females. Steiner and Davies (1957), commenting on the differences between the histopathology of cirrhosis in Uganda and in the United States, noted the almost complete absence of fatty cirrhosis in Uganda and observed that past liver cell necrosis, collapse, and a pronounced inflammatory reaction were much commoner. From this they deduced that most cases of cirrhosis in Uganda could be classified as posthepatitic and that the probable cause was viral. Similar features have been held by Gall (1960) to indicate a relation between past viral hepatitis and his posthepatitic and postnecrotic types of cirrhosis.

The distribution of the different types of cirrhosis in this series may have been distorted by the method of sampling (needle biopsy alone in over half of the cases), for nutritional cirrhosis is readily diagnosed in small specimens but the posthepatitic and postnecrotic types can present considerable difficulty. This may also be reflected in the high proportion of mixed cases. In spite of this, the paucity of nutritional cirrhosis and the preponderance of other morphological types are obvious, which confirms the earlier observations of Steiner and Davies (1957).

We have, as others, failed to show a relation between a past history of jaundice or transfusion and the presence or type of cirrhosis. Many of the patients may have had hepatitis without jaundice and attacks of jaundice may have been due to causes other than hepatitis. It is worth noting that Barker and Murray (1971) suggested that a mild or subclinical illness more commonly results in persistence of H.A.A.

There is general agreement that alcohol plays an important part in the pathogenesis of nutritional cirrhosis. Although there is still some controversy, the balance of evidence has recently shifted back to a direct toxic role of alcohol and away from any associated factor of malnutrition as the major cause (Lieber and Rubin, 1969). It has been shown in Uganda that severe protein deficiency, as occurs in kwashiorkor, does not lead to any permanent structural damage to the liver (Cook and Hutt, 1967). In the present series a history of alcoholism was obtained in 8 out of 11 patients with this type of cirrhosis but in only 9 out of 80 with cirrhosis of other types $(P<0.001)$. None of these 11 patients with a history of alcoholism had H.A.A. It would thus seem that in Uganda, as elsewhere, alcohol plays a major aetiological part in the development of the micronodular, fatty, nutritional cirrhosis and that viral infection is probably of little importance in this condition. In contrast, a clear-cut relation was found between the presence of H.A.A. and macronodular (posthepatitic or postnecrotic) types of cirrhosis in Uganda. Many were found to be carriers of H.A.A. when compared with controls or patients with micronodular cirrhosis. There was no difference in the proportion of H.A.A.-positives between the macronodular types, and morphological differences in this group may well be a reflection of the progression of the scarring process from fine to coarse with time. Alcoholism did not seem to be a significant factor in most of these cases.

These data provide support for the speculations of Steiner and Davies (1957) and of Gall (1960) that many cases of macronodular cirrhosis may be viral in origin. We are aware of the possibility that a simple association of a given disease state with the presence of H.A.A. does not necessarily imply an aetiological relation (Blumberg, Sutnick, and London, 1970). Judging by the high prevalence of anti-H.A.A. in cirrhotic patients and in controls in this study, it would seem that infection with H.A.A. must be a common event in Uganda. There is a strong suggestion (see Table I) that H.A.A. persists in a high proportion $(32.9 \%$ ) of those with cirrhosis but in a low proportion ( $3.1 \%$ ) of controls -a more likely event in the younger age groups and in males; for this we can offer no satisfactory explanation at the present time. No significant difference in the presence of H.A.A. or antiH.A.A. was found between cirrhotics with and without hepatocellular carcinoma, though it cannot be excluded that with larger numbers the observed trend towards an increase in H.A.A. carriers and a decrease in those with anti-H.A.A. might become statistically significant.

Detailed histological analysis also showed that the presence of H.A.A. in a cirrhotic patient is further associated with two types of cellular damage. One is liver cell swelling (ballooning) which, it may be recalled, is a prominent feature of acute viral hepatitis (Scheuer, 1968). The other, liver cell dysplasia, is more commonly found in cirrhotics with associated hepatocellular carcinoma than in those without, but in both groups the strength of the association is the same. Dysplasia was also present in five out of six patients in whom H.A.A. was found to persist in the presence of antibody. It is tempting to speculate that liver cell swelling may represent the earlier, more acute type of damage whereas dysplasia may be an expression of a later, more permanent change, associated, at least in some cases, with persistence of the antigen in the presence of antibody against it. Electron microscopy and immunofluorescent staining for H.A.A. have been little used so far to locate the antigen in liver cells but have been successful on some occasions (Millman, Zavatone, 
Gerstley, and Blumberg, 1969; Nowosławski, Brzosko, Madaliński, and Krawczyński, 1970; Nelson, Barker, and Danovitch, 1970; Ahmed, Huang, and Spence, 1971). It is hoped that an extension of this study by these techniques will provide further support of an association of these two types of cellular change with the presence of H.A.A.

We thank Dr. E. P. Maynard for his assistance and advice during the early part of this study and Professor R. A. B. Drury for technical facilities in the department of pathology, Makerere University, Kampala. This work is supported in part by Contract No. PH 43-67-1343 from Chemotherapy, National Cancer Institute, National Institutes of Health, Bethesda, Maryland, U.S.A. One of us (P.P.A.) gratefully acknowledges further financial assistance from Dr. A. Linsell, International Agency for Research on Cancer, Regional Centre, Nairobi, and from the Wellcome Trust, London.

This work was presented in part at an International Symposium on Liver Cancer, Kampala, Uganda, on 5 July 1971.

Requests for reprints should be addressed to Dr. P. P. Anthony, Bland-Sutton Institute of Pathology, Middlesex Hospital Medical School, London W1P 7PP.

\section{References}

Ahmed, M. N., Huang, S., and Spence, L. (1971). Archives of Pathology, 92, 66.

Barker, L. F., and Murray, R. (1971). Fournal of the American Medical Association, 216, 1970.

Blumberg, B. S., Sutnick, A. I., and London, W. T. (1970). American Fournal of Medicine, 48, 1 .

Cook, G. C., and Hutt, M. S. R. (1967). British Medical fournal, 3, 454

Gall, E. A. (1960). American fournal of Pathology, 36, 241.

Gocke, D. J., and Howe, C. (1970). Fournal of Immunology, 104, 1031

Lieber, C. S., and Rubin, E. (1969). New England fournal of Medicine, 280, 705.

Maynard, E. P., Sadikali, F., Anthony, P. P., and Barker, L. F. (1970). Lancet, $2,1326$.

Millman, I., Zavatone, V., Gerstley, B. J. S., and Blumberg, B. S. (1969). Nature, 222, 181.

Nelson, J. M., Barker, L. F., and Danovitch, S. H. (1970). Lancet, 2, 773. Nowostawski, A., Brzosko, W. J., Madaliński, K., and Krawczynski, K. (1970). Lancet, 1,494 .

Popper, H. (1966). In Controversy in Internal Medicine, ed. F. J. Ingelfinger, A. S. Relman, and M. Finland, p. 233. Philadelphia, Saunders.

Prince, A. M., Leblanc, L., Krohn, K., Masseyeff, R., and Alpert, M. E. (1970). Lancet, 2, 717.

Scheuer, P. J. (1968). Liver Biopsy Interpretation. London, Bailliere, Tindall and Cassell.

Shaper, A. G. (1970). Tropical and Geographical Medicine, 22, 161.

Sherlock, S. (1968). Diseases of the Liver and Biliary System, 4th edn. Oxford, Blackwell Scientific.

Shulman, N. R. (1970). American fournal of Medicine, 49, 669

Shulman, N. R. (1970). American fournal of Medicine, 49, 669.
Shulman, N. R., and Barker, L. F. (1969). Science, 165, 304.

Steiner, P. E., and Davies, J. N. P. (1957). British fournal of Cancer, 11, 523.

Vyas, G. N., and Shulman, N. R. (1970). Science, 170, 332.

\section{Sebum Excretion in Acromegaly}

\author{
J. L. BURTON, \\ L. J. LIBMAN, \\ W. J. CUNLIFFE,
}

R. WILKINSON,

R. HALL,

S. SHUSTER

British Medical fournal, 1972, 1, 406-408

\section{Summary}

The sebum excretion rate (S.E.R.) was measured in 20 patients with acromegaly. Eleven were untreated at the time of the measurement and nine had previously undergone surgical hypophysectomy or had received pituitary irradiation by yttrium-90 or radiotherapy. In five patients the S.E.R. was measured before and after such treatment. The mean S.E.R. in the untreated acromegalics was much greater than in a normal population and decreased significantly after successful pituitary ablation. No significant decrease in mean S.E.R. occurred in the group of patients with a poor clinical response to ablation. The correlations between S.E.R. and log serum growth hormone, plasma 11-hydroxycorticosteroid levels, and heel-pad thickness were significant, but there was no significant correlation between S.E.R. and serum protein-bound iodine levels. This suggests that the changes in S.E.R. were due to pituitary ablation but could not necessarily be attributed solely to changes in growth hormone, thyroid-stimulating hormone, or adrenocorticotrophic hormone. The association between the clinical state of the acromegaly and the S.E.R. was better than the association between acromegaly and serum growth hormone. We conclude that the S.E.R. is a useful addition to the clinical and endocrinological data used in assessing acromegaly.

\section{Royal Victoria Infirmary, Newcastle upon Tyne NE1 4LP}

J. L. BURTON, M.D., M.R.C.P., Wellcome Dermatological Research Fellow L. J. LIBMAN, B.SC., M.R.C.P., Medical Registrar (Present address: University College Hospital, London W.C.1)

W. J. CUNLIFFE, M.D., M.R.C.P., Consultant Dermatologist (Present address: General Infirmary, Leeds LS1 3EX)

R. WILKINSON, B.SC., M.R.C.P., Lecturer in Medicine

R. HALL, M.D., F.R.C.P., Professor of Medicine

S. SHUSTER, PH.D., F.R.C.P., Professor of Dermatology

\section{Introduction}

The endocrine glands play an important part in the control of sebaceous gland function. It has been shown in the rat that the pituitary has an important action in this respect although its exact role has not yet been fully elucidated (Lasher et al., 1954; Nikkari and Valavaara, 1969; Ebling et al., 1970; Thody and Shuster, 1970). We therefore investigated the effect of pituitary hyperfunction on the human sebaceous gland by studying patients with acromegaly.

\section{Method}

Seven men and 13 women aged 36-67 years with acromegaly were studied. The diagnosis of acromegaly was made after clinical and radiological assessment and measurement of serum growth hormone. Eleven patients were untreated and nine had previously been treated as follows: five had received a pituitary implant of yttrium- 90 calculated to deliver a dose of 50,000 rads; one had received an yttrium implant five years after radiotherapy to the pituitary; one had undergone surgical hypophysectomy followed by radiotherapy; and two had received only radiotherapy.

The sebum excretion rate (S.E.R.) was measured in each patient by the method of Strauss and Pochi (1961) as modified by Cunliffe and Shuster (1969). Many of the patients complained of excessive sweating in warm weather. Because the uptake of sebum by the collection papers is affected by excessive sweating the S.E.R. was estimated only at room temperature of $18^{\circ} \mathrm{C}$ or less and the subjects were given no warm drinks during the sebum collection.

In five patients the S.E.R. was measured twice (once before and once after treatment), at an interval of 8 to 20 months. The measurement was made before and after the first yttrium implant in two patients and before and after the second implant in three, the first implant having been adjudged clinically unsuccessful. The S.E.R. was measured once only in the other 15 patients. 